THE KURUME MEDICAL JOURNAL

1973 Vol.20, No.4, P.211-218

\title{
ROSETTE FORMATION : A CLINICAL IMMUNOLOGICAL ASSAY?
}

\author{
MITSUWO HARA ${ }^{1}$, BRUCE NELSON ${ }^{2}$, ALLAN B. CHINEN ${ }^{3}$ \\ AND M. MITSUO YOKOYAMA ${ }^{4}$
}

\begin{abstract}
${ }^{1}$ Department of Legal Medicine, Kurume University School of Medicine, Kurume, Japan, ${ }^{2}$ University of Hawaii, School of Medicine, ${ }^{3}$ Stanford University and ${ }^{4}$ Foundation of Molecular Medicine, 1010 Lake Hazeltine Drive, Jonathan, Minnesota, 55318
\end{abstract}

(Received for publication November 20, 1973)

Immunology today promises many hopeful developments in the understanding of cancer, immunological behavior of autoimmune diseases, organ transplantation and other allied diseases.

Although our knowledge of the exceedingly complex immune system is rather meager, research is constantly expanding for the resolution of the complexity. Clinical approach has generally lagged behind considerably, however, due to the lack of clinically feasible assays and diagnostic tests, or due to a paucity of reliable and specific knowledge of basic mechanisms; the techniques used in research are far too complex and costly for clinical exploitation.

In 1964 Nota $^{1)}$ and Zaalberg' ${ }^{2)}$, working independently, described a phenomena called immunocyto-adherence; the agglutination of cells, such as lymphocyte surrounded by erythrocytes. This was applied by Biozzi ${ }^{3)}$ to examine antibody producing cells, and further work rapidly followed. The lymphocyte surrounded by the erythrocytes to form a flower-like pattern, the phenomenon was called a rosette formation. Much still remains unclear about the exact mechanism and significance of the formation, but many studies suggest that the rosette formation is potentially a simple, specific, reproducible, and highly informative immunological test, possibly suitable for clinical application.

The general theory of the rosette formation or test is that certain lymphocytes secrete antibodies, or possess cell surface receptors to certain specific antigens. These secreted-antibodies or antigen-receptors bind the antigen to the lymphocyte. If the antigens are present on the surface of other cells such as red blood cells (RBC), or if the antigens can be artificially put on the surface of RBC's, these RBC's will bind to the lymphocyte, producing the easily visible rosette ${ }^{4}$. Since the sensitivity of lymphocytes to specific antigens reflects the immunity that a person possesses, the rosette test can provide us with a simple way of examining the state of a patient's immunological system.

\section{CLINICAL APPLICATIONS}

Recent literature is full of attempts to apply the rosette test to numerous immunologically-related diseases. Lymphocytes from rheumatoid arthritis patients have been observed to form rosettes even though no serum rheumatoid factor was detected 5) 6). RBC's 
coated with immunoglobulin were used in this test, the so-called rheumatoid rosette test. Although the number of observed rosettes did not correlate with the titre of rheumatoid factor when the latter was detected, there was a positive correlation with the intensity of the patient's experienced pain. The rosette test apparently unifies seronegative and seropositive cases of rheumatism, and may be a better indicator than previous serum tests. The rheumatoid rosette test has also been applied to cases of psoriasis, with positive, and apparently specific results; psoriatic lymphocytes bind to immunoglobulin coated RBC's ${ }^{7}$.

Transplantation studies have also used the rosette test. Rather than using the lengthy and costly lymphocyte blastformation or leukocyte migration assays, the rosette test has been used to monitor the activity of lymphocytes during immunosuppressive therapy. While working on kidney transplant

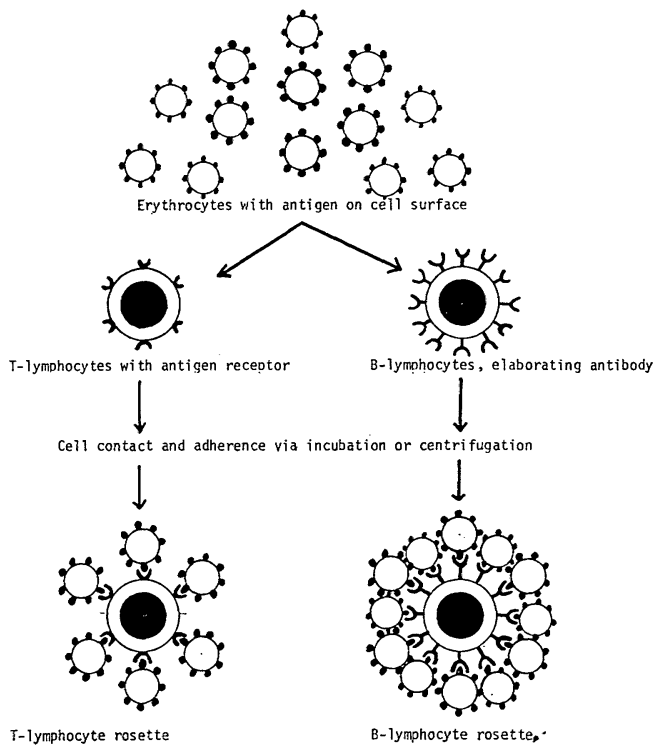

Fig. I The Rosette Test, with $\mathrm{B}$ and $\mathrm{T}$ cell type lymphocytes. patients, Bewick et al. ${ }^{8)}$ and Forest et al. ${ }^{9)}$ found that imminent rejection episodes could be detected before damage to the transplanted organ occurred.

This resulted in an improvement in the overall function of the transplant. The rosette test has also been used to accurately assay the titres of anti-lymphocyte serum or globulin (ALS or $A L G) 10$ 11) 12). The rosette assay correlated well. with the in vivo immunosuppression obtained by the tested ALS or ALG, as measured by skin graft rejection in experimental animals.

The rosette test has also been applied to cases of $\mathrm{Rh}$ negative individuals who were sensitized by $\mathrm{Rh}$ positive, thyroiditis, glomerulonephritis, drug sensitization, alcoholic cirrhosis and leukemia 4) 13) 14) 15).

\section{TECHNICAL ASPECTS}

There are several versions of the test. Essentially lymphocytes (and of ten macrophages) are isolated from other leukocytes. A variety of isolation techniques can be used, such as sedimentation, Ficoll/Hypaque (or Isopaque) density gradient separation, or column selective adherences, etc. In some cases macrophages are also eliminated to give a relatively pure lymphocyte preparation. The purified lymphocyte suspension is then mixed with a suspension of RBC from varying species sources and sheep $\mathrm{RBC}$ are very commonly used (Fig. 1). These RBC may be pre-coated with various antigens, immunoglobulins, drugs, polysaccharides, or haptens, depending on the purpose of the test Bentonite particles have also been used in place of erythrocytes. The mixture of lymphocytes and RBC are incubated or centrifuged to facilitate contact and adherence although centrifugation technique is variable. Incubation is customarily at $37^{\circ}, 4^{\circ}$ or $0^{\circ} \mathrm{C}$, for varying 
durations. The preparations are resuspended after incubation or centrifugation to disperse weak non-specific clusters, and the number of rosettes is counted under a microscope. A cluster is usually considered to be a rosette if 4 to $6 \mathrm{RBC}$ adhere to the central lymphocyte (Fig. 1). There is no standard technique, and there are very strong indications that different incubation temperatures and times for assay are very different in types of rosette forming cells (RFC). Increasing the RBC/ lymphocyte ratio generally also results in increasing rosette counts. The $\mathrm{pH}$ is rather critical ${ }^{16)}$ and differing concentrations of ions, particularly $\mathrm{Mg}^{++}$ and $\mathrm{Ca}^{++}$, elicit variances in the number of observed rosettes ${ }^{17}$ ). Due to great diversity in technique, it is exceedingly difficult to compare the numerous studies on rosette formation ; what exactly is measured with which technique is often not clear.

\section{THE NATURE OF ROSETTE FORMING CELLS}

Despite the promising possibilities of clinical applications, it is evident that we must be cautious in any enthusiasm. for the test. Besides technical uncertainties, we do not clearly know the basic mechanism involved in rosette formation, and hence cannot accurately evaluate the significance of the test. Many studies suggest divergent, and sometimes contradictory conclusions, and the discussion continues.

Current reseach indicates that there are actually three possible mechanisms to rosette formation, in general 18): a) non-immunological affinity, involving a variety of factors, including perhaps those forces that normally hold tissue together; b) non-specific immunological binding, as for example a lymphocyte binding to virtually any type of antigen-antibody complex; and c) immunological binding, the specific antigen-antibody or antigen-antigenreceptor interaction. Clearly it is (c) that we are interested in, the case of true immunological and specific rosettes : (a) and (b) are obscuring elements that can compromise the significance of a rosette test. Indications are that the test conditions are crucial in eliminating (a) and (b) for (c) 19) 20).

The rosette forming cell ( $\mathrm{RFC}$ ) involved in true rosettes are a very heterogeneous population. They include macrophages, small, medium, large, and blast lymphocytes, and plasmacytes ${ }^{21}$ ) In many cases, there is a background level of $\mathrm{RFC}$ even without challenge to the specific antigen or RBC involved.

In man, for example, sheep RBC elicits a low level of rosette formation without prior immunization ${ }^{22)}$. Background RFC tend to consist of macrophages and small or medium lymphocytes. After challenge to the specific antigen or RBC, large lymphocytes, blastocytes, and plasmocytes appear, generally in that sequence ${ }^{21}$. Studies indicate that the post-immunization increase in RFC results from the proliferation of the background population of RFC, as is consistent with the clonal selection theory of immunity 4)21/23).

The number of RFC detected is highly variable, influenced by experimental conditions. For rosettes involving RBC that have been coated with antigenic factors, the density of the coating is crucial $^{20}$. If too dense, the background level of RFC increases so much that no difference is noticeable between the background and post-immunization RFC counts. The number of RFC also depends on the lymphoid organ studied, and the antigenic factor being tested.

A tentative picture emerges from various studies, and the lymphocytes involved in rosette formation are deriv - 


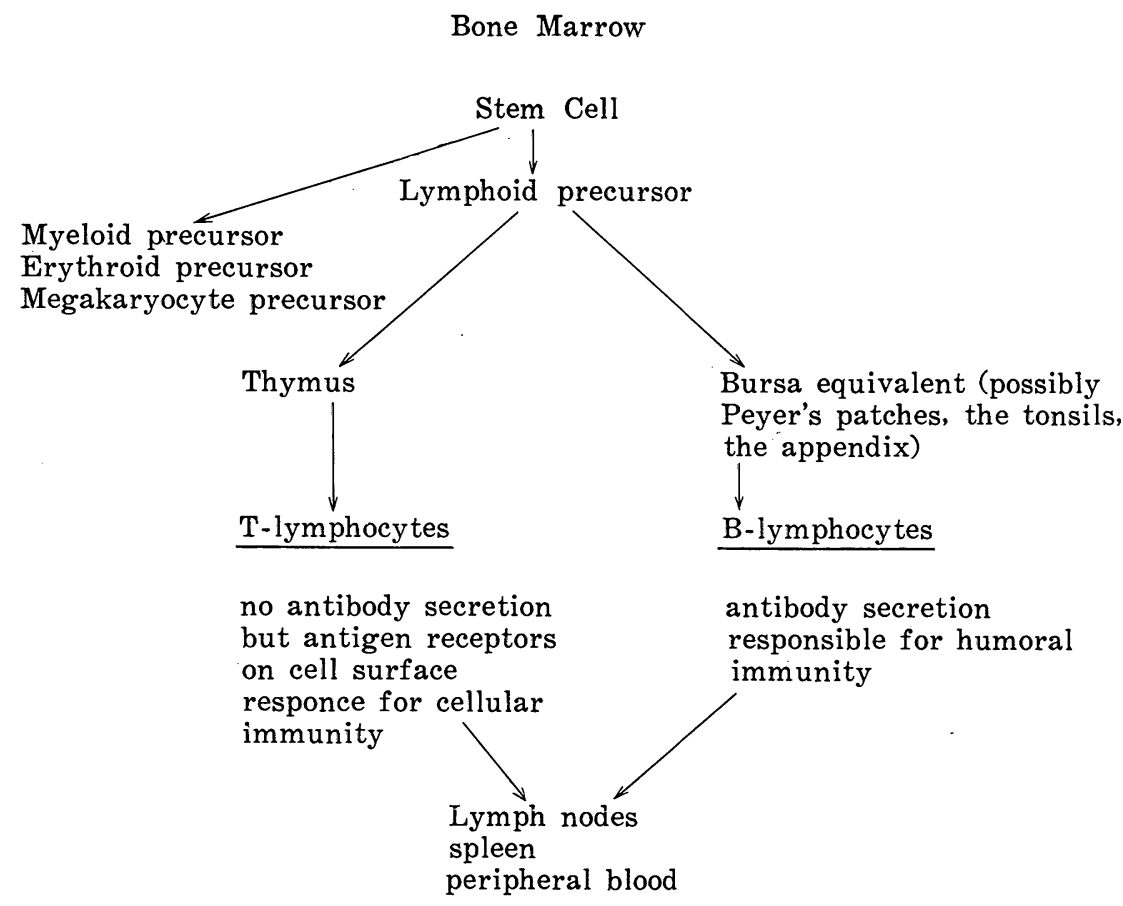

Fig. II Schematic of the origin, differentiation and function of the $\mathrm{B}$ and $\mathrm{T}$ lymphocytes.

ed from at least two major populations (Fig. 2), the T-or thymus-derived cell, and B-or bursa-equivalent lymphocyte 20)24)25)26). T-lymphocytes are associated with cellular-mediated immune phenomena, and generally circulate in the peripheral blood stream. B-lymphocytes, found primarily in the bone marrow, are thought to secrete antibodies and mediate the humoral aspect of immunity. B-cells generally also have complement receptor sites, and/or immunoglobulin on their cell surfaces, as well as the capacity to form plaques in hemolytic gel assays. T-lymphocytes lack these properties, but in some cases, possess specific antigenic determinants or markers. In the mouse this is the theta $(\theta)$ antigen, for example.

Observations indicate that there are two rosette forms ${ }^{14) 16) 20) 22)}$ both easily distinguishable. One form involves multiple layers of RBC around the central RFC and it is thought that this is the rosette of the B-lymphocyte (Fig. 1). The other rosette consists of a central RFC, thought to be a T-lymphocyte, surrounded by a simple monolayer of $\mathrm{RBC}$. The multiple layer rosette apparently results from the elaboration of antibodies by the B-lymphocyte, with consequent haemagglutination. T-rosette formation appears to involve microprojects from the lymphocyte surface, as revealed by electron microscopy ${ }^{14}$ ) and these microprojects bind to the RBC surfaces. Cytochalasin B, which specifically disrupts cellular contractile activity, abrogates rosette formation. Apparently rosette formation also depends on metabolism by the lymphocyte; metabolic poisons prevent rosette for- 
mation and pretreatment with trypsin also destroys rosettes ${ }^{19)}$. Moreover, antigen binding by T-lymphocytes appears to depend on having the antigen embedded in a cell membrane, as on an erythrocyte $^{20)}$. This contrasts with Blymphocytes which are capable of binding soluble antigen.

It appears that many B-rosettes are obtained when the lymphocyte/RBC mixture is incubated at $37^{\circ} \mathrm{C}$, while primarily T-rosettes appear during incubation at $0^{\circ} \mathrm{C}$ or $4{ }^{\circ} \mathrm{C}^{20}$ ). This is attributed to the prevention of antibody secretion by B-cells at low temperatures. This temperature dependency is not definitely established yet, but might furnish a means of isolating the $\mathrm{T}$ - and B-lymphocyte lines of RFC, for study.

The evidence for the two types of RFC comes from numerous sources. Embryological studies indicate that in mice and men RFC is first detectable in the thymus, and then in the peripheral blood, spleen, and lymph nodes 27) 28). This strongly suggests that at least part of the RFC are T-cells. Moreover, neonatal thymectomy of mice sharply reduces the RFC count ${ }^{20}{ }^{28}$. By contrast, bursectomy in the chicken, an operation thought to remove the source of B-cells, reduces or eliminates $\mathrm{RFC}^{\prime}{ }^{29)}$. Use of the plaque forming assay which detects lymphocytes that can secrete antibody, i. e. usually the B-cells, indicates that the RFC population and the plaque forming cells are essentially independent. However a substantial degree of overlap was detected by some studies ${ }^{30}$ ) 31 ). With the mouse, where T-lymphocytes are marked with the theta $(\theta)$ antigen, studies have shown that RFC, both with and without the antigen, are detectable ${ }^{2)}$. In chronic lymphatic leukemia, thought to involve predominantly the bone marrow originating B-cells, leukemic cells essentially do not form rosettes ${ }^{15}$. Obser- vations indicate that in Wiskoff-Aldrich syndrome, or the Nezelof syndrome, conditions associated with impaired cell-mediated immunity, the RFC counts are eliminated or depressed ${ }^{27}$. For cases of acquired hypogammaglobulinemia, RFC are often normal; the B-cells are generally thought to be defective ${ }^{27}$. Other studies ${ }^{32)}$ e. g., of ataxia telangiectasia, suggest that RFC are not solely T-cells. These are only a small part of the experimental data on the subject, but it should be made clear that the nature of the RFC is far from settled, although the data is consistent with the tentative picture.

The inhibition of rosette formation by various factors has also been examined ${ }^{33)}{ }^{34}$. . Passive administration of excess antibody in vivo depresses the number of detectable RFC ${ }^{35)}$. Passive antibody may act by antigen competition, or negative feed back. It is a common phenomena, however, not restricted to RFC.

As shown in Figure 3, lymphocytes treated with anti-immunoglobulin sera

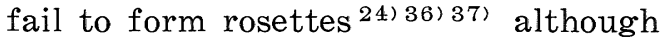
the exact target of the antisera is not known. Antisera to the light and heavy chains of immunoglobulin apparently inhibit B-cells, while only anti-light chain sera appears to affect T-cells. These results suggest that determinants similar to the immunoglobulin fractions exist on the B-and T-cells. The alpha $(\alpha)$ globulin fraction of human plasma has also been observed to inhibit rosette formation, but this, again, is not specific to $\mathrm{RFC}^{38}$ ).

Azathioprine, ALG, and ALS, as well as other immunosuppressive drugs, also inhibit rosette formation ${ }^{31}$ ) as mentioned previously. ALS and ALG appear to act primarily on T-cells, since rosette formation capacity can be reconstituted by injection of thymocytes, and ALG treatment results in depletion of the 
thymus and lymph nodes. Azathioprine has a reversible inhibitory effect on $\mathrm{T}$-cells, but it is not clear whether the drug works directly on the lymphocyte alone. Some evidence indicates that thymosin, or some other thymus hormone, is necessary for rosette formation ${ }^{37)}$ and that azathioprine treatment may interfere with the hormone. It is generally thought, however, that azathioprine does at least act to modify the T-cell, probably by inactivating the membrane on the antigen receptor.

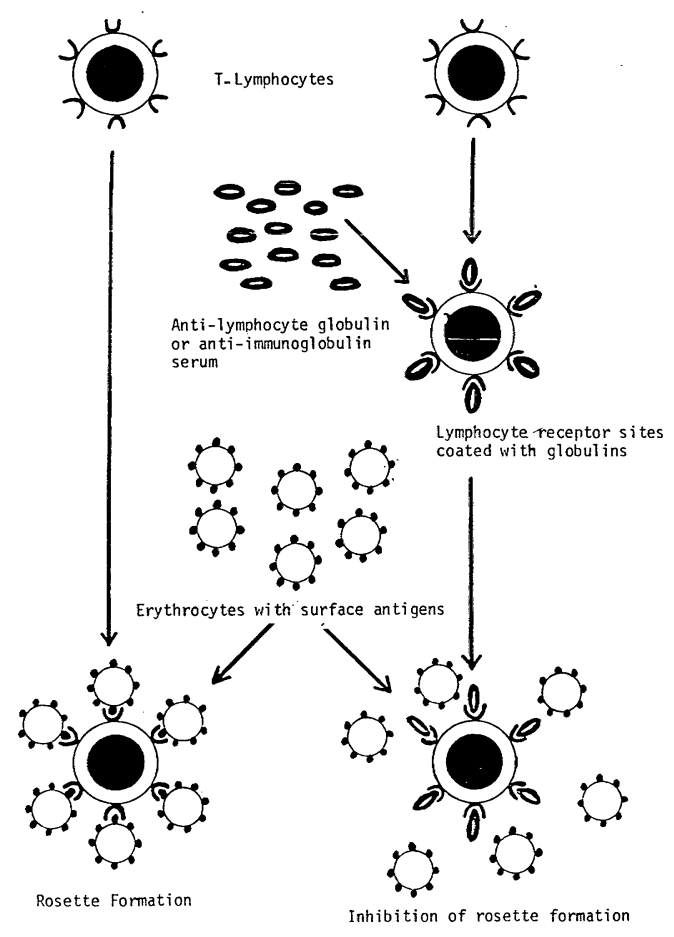

Fig. III A model of antibody-mediated rosette inhibition.

\section{CONCLUSION}

The rosette test appears to be a promising clinical tool as a monitor of immunological diseases. There are many uncertainties, however, which limit its significance and reliability at the present. Preliminary investigations in clinical uses raises many interesting possibilities which basic research may actualize. There remains the intriguing hope that the rosette test may be used to examine the immunology of cancer, particularly the enhancement phenomena, as well as the many perplexing autoimmune diseases, from multiple sclerosis to systemic lupus erythematosus.

This paper is No. 113 from the Foundation of Molecular Medicine and this study was supported in part by Kallestad Laboratories, Inc., 1000 Lake Hazeltine Drive, Chaska, Minnesota, 55318.

\section{REFERENCES}

1 ) Nota, N.R., Liacopoulos-Brit, M., Stiffel, C. et al.: "L'immunocyto-adherence; une methode simple et quantitative pour l'etude in vitro des cellules, productrices d'anticorps." C. R. Acad. Sci. (Paris), 259, 1277, 1964.

2) ZAALberg, A.B.: A simple method for detecting single antibody-forming cells. Nature (London), 202, 1231, 1964.

3 ) Biozzi, G., Stiffel, C., Mouton, D. et al. : A kinetic study of antibody producing cells in the spleen of mice i. v. injected with sheep erythrocytes. Immunology, 14 7, 1968.

4) BACH, J. F. : Antigens binding cells. In Cell-mediated Immunity: In Vitro correlates ed. J. P. Revillard, 1971, University Park Press, Baltimore. p. 51-74.

5 ) Bach, J. F., Delricu, F. and Delbarre, F.: The rheumatoid rosette $:$ a diagnostic test unifying seropositive and seronegative rheumatoid arthritis. Amer. J. Med. 49, 213, 1970.

6 ) Serre, H., Simon, L., Mandin, J., et al. : Recherche du facteur rheumatoide par la technique des rosettes. La Presse Medicale. 79, 2110, 1971.

7 ) Rimbaud, P., Meynadier, J., Guilhou, J., et al.: Presence of rheumatoid rosettes in 
psoriasis. Nouvelle Presse Medicale, 1, 1844, 1972.

8 ) Bewick, M., OgG, C. S., Parsons, V. et al. : Further assessment of rossette inhibition test in clinical organ transplantation. Brit. Med. J., 3, 491, 1972.

9 ) Forrest, R., Hallgren, R. and Fjellst ROM, K. : Rosette inhibition test and renal transplantation. Brit. Med. J., 4. 361, 1972.

10) BACH, J. F. : Les serums antilymphocytes. I. et II. Europ. J. Clin. Biol. Res. 15, 28 , et $258,1970$.

11) $\mathrm{BACH}$, J. F. : In vitro assay for antilymphocyte serum. Fed. Proc. 29, 120, 1970.

12) Kelly, G. E., Mears, D. C. and Sheil, A. B. : Relationship of the immunosuppressive potency of antilymphocyte globulin to three in vitro tests. Close correlation with rosette inhibition. Transplantation, 12, 443, 1971.

13) Bert, J. M., Bubouis, F. B., Balmes, J. L. et al. : Natural rosette test in alcoholic cirrhosis. La Nouvelle Presse Medicale. 1, 1294, 1972.

14) Elson, C. J., Bradley, J. and Howells, R. E. : The mechanism of rosette formation between $\mathrm{Rh}$ (D) -positive erythrocytes and peripheral blood lymphocytes from $\mathrm{Rh}$ isoimmunized individuals. The role of surface microprojections. Immunology, 22, 1075, 1972.

15) Ross, G. D., Rabellino, E. M., Polley, M. F., et al.: Combined studies of complement receptor and surface immunoglobulin-bearing cells and sheep erythrocyte rosette forming cells in normal and leukemic human lymphocytes. J. Clin. Invest. 52, 377, 1973.

16) Chaves, M. A. and Arranhado, E. : Rosette formation and immunosuppressive agents. Lancet, I, 42, 1972.

17) Parcells, A.J. : Rosette formation. Lancet. II, 709, 1972.

18) Siegel, I.: Mechanisms of rosette formation. Brit. Med. J., 4, 297, 1972.

19) Morton, H. J. and Clunie, G. J. : The rosette inhibition test : technical considerations. Transplantation, 14, 211, 1972.

20) Bach, J. F., Biozzi, G., Greaves, M. F. et al. : Summary of round-table discussions on the technical aspects of the rosette test. Transpl. Proc. 4, 335, 1972.

21) Biozzi, G., Stiffel, C., Mouton, D. et al. :
Morphology and differentiation of rosette forming cells during the immune response. Transpl. Proc. 4, 339, 1972.

22) Jondal, M., Holm, G. and Wigzell, H. : Surface markers on human $\mathrm{T}$ and $\mathrm{B}$ lymphocytes. I. A large population of lymphocytes forming nonimmune rosettes with sheep red blood cells. J. Exper. Med. 136, 207, 1972

23) Burnet, F. M. : The clonal selection theory of acquired immunity. 1959. University Press, Cambridge.

24) Thursh, D. R., Emeson, E. E., Ciacomelli, F., et al. : Ultra-structure and radioautography of rosette forming cells of normal and immunized mice. Cellular Immunol. 4, 218, 1972.

25) Greaves, M. F. and Hogg, N. M. : Inhibition of rosette formation by antisera to cell surface determinants : an approach to the antigen receptor problem. Transpl. Proc. 4, 351, 1972.

26) Elson, C. J., Allan, D., Elson, J., et al. : The relationship between the morphology of rosette forming cells and their mode of rosette formation. Immunology, 22, 291, 1972.

27) Wybran, J., CARr, M. C. and Fudenberg, H. H. : The human rosette-forming cell as a marker of a population of thymus derived cells. J. Clin. Invest. 51, 2537, 1972.

28) Wybran, J. and Fudenberg, H. H. : Rosette formation: a test for cellular immunity. Transact. Assoc. Amer. Phys. 134, 239, 1971.

29) Kiszkiss, D. F., Chor, Y.S. and Good, R. A. : The effect of surgical bursectomy and irradiation of rosette-forming cells in the chicken. J. Immunol. 109, 1405, 1972.

30) Wilson, J. D. : The relationship of antibody forming cells to rosette forming cells. Immunology, 21, 223, 1971.

31) Hunter, P., Munro, A. and McConnel, I. : Properties of educated $\mathrm{T}$ cells for rosette formation and cooperation with $\mathrm{B}$ cells. Nature (New Biology), 236, 52, 1972.

32) Y $\mathrm{ATA}$, J. and Goy A, N. : Rosette formation with sheep erythrocytes. Lancet, 1, 42, 1972.

33) $\mathrm{B}_{\mathrm{ACH}}, \mathrm{J} . \mathrm{F}$.: Antigen recognition by T cells and its suppresion significance and origin of rosette-forming cells. Ann. Rheum. Dis. 30, 565, 1971. 
34) Greaves, M. F.: Biological effects of anti immunoglobulins: evidence for immunoglobulin receptors on $\mathrm{T}$ and $\mathrm{B}$ lymphocytes. Transpl. Rev. 5, 45, 1970.

35) UhR, W. J. and Moller, G. : Regulatory effect of antibody on the immune response. In Advances in Immunology, Ed. F. J. Dixon, Jr. and H. G. Kunkle, 1968, Academic Press, p. 81.

36) LANCE, E. M. : The selective action of antilymphocyte serum on recirculating lym- phocytes: a review of the evidence and alternatives. Clin. Exper. Immunol. 6, 789, 1970.

37) BACH, J. F. and DARdenne, M. : Thymus dependency of rosette forming cells; evidence for a circulating thymus hormone. Transp. Proc. 4, 345, 1972.

38) Glaser, M., Ofek, I. and Nelken, D. : Inhibition of plaque formation, rosette formation and phagocytosis by alpha globulin. Immunology, 23, 205, 1972. 